\title{
Identificación y caracterización de refugios de quirópteros en la Ciudad de Corrientes, Argentina
}

\author{
Bastiani, C.E.; Ramírez, N.N.; Alegre, E.A.; Ruiz, R.M.
}

Cátedra Salud Pública, Facultad de Ciencias Veterinarias, Universidad Nacional del Nordeste, Sargento Cabral 2139, Corrientes (3400), Argentina. Tel/fax 03794-425753. E-mail: raquel_monicaruiz@hotmail.com.

\begin{abstract}
Resumen
Bastiani, C.E.; Ramírez, N.N.; Alegre, E.A.; Ruiz, R.M.: Identificación y caracterización de refugios de quirópteros en la Ciudad de Corrientes, Argentina. Rev. vet. 23: 2, 104-109, 2012. Los estudios sobre quirópteros y sus relaciones ecológicas son escasos en el nordeste argentino. Los objetivos del trabajo fueron localizar y caracterizar refugios, así como identificar las especies de murciélagos halladas, para establecer datos sobre la actual ecología urbana de estos mamíferos en la Ciudad de Corrientes. Mediante observaciones de los investigadores y entrevistas personalizadas realizadas al azar en diferentes barrios, se localizaron refugios durante el período marzo 2010 a mayo 2012. Se evaluó la altura de los refugios y se los clasificó en naturales y artificiales, estos últimos habitados o no por el hombre. Se identificaron especies arbóreas utilizadas como refugios, se estimó la distancia entre éstas y las viviendas humanas y se estableció género y especie de murciélagos capturados. La captura, realizada en forma manual y por trampa balde, fue menor durante el período invernal. Se caracterizaron 38 refugios, $53 \%$ naturales y $47 \%$ artificiales, sin encontrarse diferencias significativas entre ambos ( $p>0,05)$. Los refugios fueron más numerosos en viviendas habitadas por el hombre $(92,31 \%)$ que en aquéllas deshabitadas. Se identificaron siete especies arbóreas, Fraxinus americana fue la más frecuentemente utilizada como refugio, quizás por su abundancia en la ciudad y por sus características favorables para los insectos. Los refugios naturales fueron hallados a menos de $10 \mathrm{~m}$ de distancia de edificaciones y a no más de $5 \mathrm{~m}$ de altura con respecto al suelo. Se capturaron 76 murciélagos pertenecientes a 3 familias y 9 especies, 93\% insectívoras. Se hallaron dos especies de la familia Molossidae compartiendo refugio, Eumops patagonicus y Molossus rufus. Tanto los refugios naturales como los artificiales se encontraron en áreas con presencia de vegetación, luz artificial y alta densidad de insectos. La escasa proximidad de los refugios con viviendas humanas demuestra la eficiente adaptabilidad de diferentes géneros y especies de quirópteros de la Ciudad de Corrientes.
\end{abstract}

Palabras clave: murciélago, refugios naturales y artificiales, vegetación, vivienda humana, ecología, Argentina.

\begin{abstract}
Bastiani, C.E.; Ramírez, N.N.; Alegre, E.A.; Ruiz, R.M.: Identification and characterization of bats shelters in Corrientes City, Argentina. Rev. vet. 23: 2, 104-109, 2012. In Argentina there are few studies regarding bats and the ecological aspects related to them. The objectives of this study were to determine and characterize bat shelters and to identify inhabiting species, as well as to establish data regarding current urban ecology of these mammals in Corrientes, Argentina. Through direct observations and interviews conducted randomly in different neighborhoods, shelters were located during the period of March 2010 to May 2012. Height where shelters were located was considered, and they were classified into "natural" and "artificial", inhabited or not by man. Species of trees used as shelters, distance between them and human dwellings and genus and species of bats were considered for this study. Animal trapping was lower during winter. Thirty eight shelters were identified, being 53\% natural and $47 \%$ artificial, with no significant differences $(p<0.05)$. Seven species of trees were identified, being Fraxinus americana the most frequent with favorable characteristics for insects.Natural shelters were located mostly $10 \mathrm{~m}$ from buildings and at a height greater than $5 \mathrm{~m}$. A total of 76 bats were captured, belonging to 3 families and 9 species, being $93 \%$ of them insectivorous. Two species were found to share shelters, Eumops patagoni-
\end{abstract}

Recibido: 1 junio 2012 / Aceptado: 15 agosto 2012 
cus and Molossus rufus, an interesting association for behavioral studies. Both natural and artificial shelters were found in areas of vegetation, artificial light and high density of insects. The short proximity of shelters to human populations demonstrates the efficient adaptability of the different genera and species of bats from the City of Corrientes.

Key words: bat, natural and artificial shelters, vegetation, human housing, ecology, Argentina.

\section{INTRODUCCIÓN}

Los estudios en Argentina sobre quirópteros son escasos, más aún aquellos que hacen referencia a sus refugios. Son muchos los aspectos a tener en cuenta para el estudio de los murciélagos, desde su biología: hábitat, reproducción, aspectos comportamentales, como también la implicancia que tienen estos animales dentro de la cadena epidemiológica de varias enfermedades. Diferentes investigaciones apuntan a dos tipos de hábitat, por un lado grandes zonas naturales con escasa modificación antrópica y por otro los ecosistemas urbanos dentro de los cuales los quirópteros se encuentran en estrecho contacto con el hombre. Es insuficiente la información sobre aspectos ecológicos de comunidades de murciélagos que habitan la ciudad de Corrientes, Argentina, específicamente los referidos a las características de sus refugios y diversidad específica.

Los murciélagos son animales no deseados por el ser humano, quizás por su aspecto físico o por el problema higiénico que generan en viviendas utilizadas como refugios, debido a la acumulación de excrementos y orina por lo que su permanencia en las mismas repercute en el deterioro de las estructuras edilicias ${ }^{23}$. Por otro lado, estos animales están asociados a diferentes enfermedades, entre ellas la tan temida rabia ${ }^{1}$, 14, 20, 22, 24 .

Sin embargo, deberían tenerse en cuenta los beneficios que brindan los murciélagos por intervenir en el equilibrio de los ecosistemas, actuando como controladores biológicos de abundantes clases de insectos que pueden participar como transmisores de enfermedades o como plagas para los cultivos ${ }^{2}$. También son excelentes dispersores de semillas y grandes polinizadores, ayudando a la recuperación de bosques y montes, fuertemente amenazados en la actualidad por el creciente desarrollo agrícola impulsado por el avance de la soja ${ }^{17}$. Así, en el nordeste de Argentina, en las provincias de Misiones, Corrientes, Chaco y Formosa, se encuentran muchas especies de murciélagos cuya alimentación está basada en néctar, polen, flores, frutos e insectos, circunstancia que colabora de manera trascendental en el mantenimiento de un ecosistema equilibrado ${ }^{4}$.

La ciudad de Corrientes está ubicada en la eco-región del chaco oriental, zona que ha sufrido una histórica devastación por la extracción descontrolada de especies arbóreas nativas, por la explotación agrícola-forestal y por el sobrepastoreo ganadero ${ }^{11}$. Habitan en esta ciudad unas 358.000 personas, distribuidas en 96.000 viviendas, las que para aislar el calor y mantener temperaturas confortables en el interior de las habitaciones, en un $78 \%$ presentan cielorraso en sus techos, formando en algunos casos amplios desvanes o áticos ${ }^{15}$. Estos sitios, en el caso de contar con defectos edilicios, pueden ser utilizados por los murciélagos como refugios artificiales, debido a que presentan temperaturas entre $30^{\circ}$ y $50^{\circ} \mathrm{C}$, humedad relativamente mayor a la externa y ventilación deficiente, características favorables para el asentamiento de colonias de quirópteros ${ }^{2}$.

Con relación a la arborización urbana, en las veredas y parques correntinos se encuentran ejemplares de especies nativas como el Schinopsis balansae y Aspidosperma sp (quebracho colorado y blanco), Jacaranda mimosifolia (jacarandá), Tabebuia sp (lapacho), Chorisia sp (palo borracho) -entre otras- y varias especies exóticas como Fraxinus americana (fresno americano), Hovenia dulcis (árbol de las pasas), Mangifera indica (mango), Arecastrum romanzofianum (pindó), Washingtonia filifera (palmera washingtonia), Eucalyptus $s p$ (eucalipto) y otros ${ }^{9}$. Esta vegetación sirve como fuente de alimento y refugio a muchas especies de murciélagos.

La información sobre identificación de refugios de quirópteros, su caracterización y determinación de las especies que los habitan, es de suma importancia para establecer objetivamente en qué circunstancias se comportan como beneficiosos y en cuales dejan de serlo para la población humana. Es por ello que el objetivo general del presente trabajo fue localizar diferentes refugios de murciélagos dentro de la Ciudad de Corrientes, caracterizar a cada uno de ellos e identificar las especies de quirópteros halladas para establecer características de la actual ecología de estos mamíferos en nuestra ciudad.

\section{MATERIAL Y MÉTODOS}

El estudio se realizó en la Ciudad de Corrientes, Argentina, situada a orillas del Río Paraná entre las coordenadas geográficas: $27^{\circ} 26^{\prime} 57.55^{\prime \prime} \mathrm{S}$ y $58^{\circ} 52^{\prime}$ $55.18^{\prime \prime}$ O. La zona presenta un clima cálido subtropical sin estación seca, con una temperatura anual promedio de $20^{\circ} \mathrm{C}\left(\right.$ de 10 a $33^{\circ} \mathrm{C}$ ) y régimen pluviométrico medio de $1.400 \mathrm{~mm}^{21}$. Dentro de la ciudad se tomó como límite del área de estudio la jurisdicción de la Municipalidad local.

La recolección de información para identificar los refugios utilizados por murciélagos fue a través de entrevistas personalizadas no estructuradas, realizadas al 
azar en diferentes barrios de la ciudad, con entrega adicional de folletos relacionados al tema. Otra fuente de información fueron las denuncias personales recepcionadas por la Cátedra de Salud Pública de la Facultad de Ciencias Veterinarias (UNNE), que revelaron la presencia de murciélagos en domicilios particulares. Por otro lado la identificación de los refugios fue realizada por el grupo de investigación con salidas a terreno en horarios diurnos, crepusculares y nocturnos para una localización visual y auditiva como así también para la identificación de sus rastros (guano, manchas características en la pared, olor particular, restos óseos y otros). Estas actividades se realizaron en diferentes barrios y en las cuatro estaciones del año durante el período marzo 2010 a mayo 2012.

Los refugios se clasificaron en naturales, si se trataban de refugios ubicados en diferentes especies arbóreas y en artificiales si éstos se encontraban en construcciones realizadas por el hombre; el último grupo a su vez se clasificó en habitado o no por personas, registrando las características de la construcción. Se identificaron las especies arbóreas utilizadas como refugios y se estimó la distancia entre éstas y la vivienda humana más cercana, agrupando las distancias en una escala en metros compuesta por los siguientes grupos: menor a $3 \mathrm{~m}$, entre 3 y $5 \mathrm{~m}$ y entre 6 y $10 \mathrm{~m}$. Los refugios naturales y artificiales fueron clasificados según su altura aproximada en relación al nivel del suelo: menos de 5 $\mathrm{m}$, entre 5 y 10 , entre 11 y 15 y más de $15 \mathrm{~m}$.

Los métodos de captura se aplicaron de acuerdo a diferentes circunstancias, según tipo de refugio, ubicación y momento del día en que se realizó la actividad. Los elementos para captura fueron redes de niebla, redes de mano, trampa balde o directamente con la mano protegida con guantes de cuero. Una vez capturados, los animales fueron transportados en bolsas de lienzo al laboratorio antemencionado, donde se realizó la identificación de familia, género y especie según claves preexistentes ${ }^{4,6}$. También fueron clasificados por su hábito alimenticio y por el tipo de refugio en el que fueron hallados. Luego se procedió a realizar la eutanasia
Tabla 1. Especies arbóreas y número de refugios naturales hallados.

\begin{tabular}{lc}
\hline especies arbóreas & frecuencia \\
\hline Fraxinus americana & 7 \\
Mangifera indica & 3 \\
Hovenia dulcis & 3 \\
Arecastrum romanzofianum & 3 \\
Washingtonia filifera & 1 \\
Eucalyptus sp & 1 \\
Tabebuia sp & 1 \\
sin identificar & 1 \\
total & 20 \\
\hline
\end{tabular}

Tabla 2. Tipo y número de refugios artificiales hallados.

\begin{tabular}{lc}
\hline refugios artificiales & frecuencia \\
\hline techos de viviendas con cielorraso & 8 \\
desvanes o áticos & 2 \\
edificio en construcción detenida & 1 \\
pozo de agua & 1 \\
fachada de edificio & 1 \\
poste de luz & 1 \\
chimeneas de hogares & 2 \\
techo de vivienda sin cielorraso & 1 \\
quincho & 1 \\
total & 18 \\
\hline
\end{tabular}

de los murciélagos capturados, siguiendo las normas de buen trato animal, para el desarrollo de otros estudios.

\section{RESULTADOS}

Durante el período de trabajo, se identificaron 38 refugios (Figura 1); el 53\% se clasificó como natural y correspondió a diferentes especies arbóreas, cuyos nombres y frecuencia se muestran en la Tabla 1. La distancia de estos refugios a las viviendas en mayor porcentaje fue menor a los $3 \mathrm{~m}$ (Figura 2). Los refugios artificiales constituyeron el $47 \%$, dentro de los que se encontraron diversas construcciones hechas por el hombre, las que se pueden apreciar en la Tabla 2. De

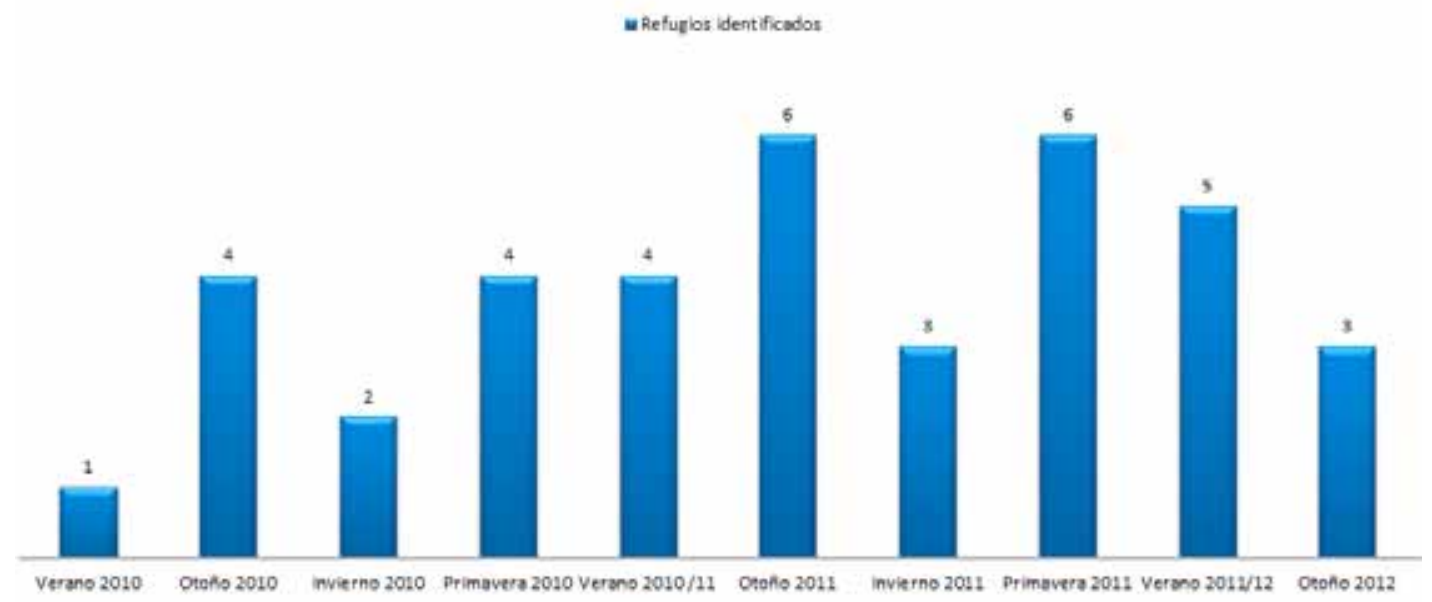

Figura 1. Número de refugios de murciélagos identificados en distintas estaciones durante el período marzo de 2010 a mayo de 2012. 


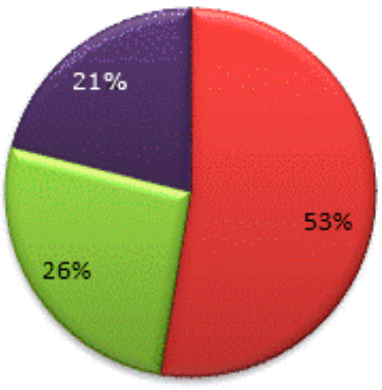

Menos de $3 \mathrm{~m}$

Mentre $3 \mathrm{~m}$ y $5 \mathrm{~m}$

Dentre $6 \mathrm{~m}$ y $10 \mathrm{~m}$

Figura 2. Distancia desde los refugios naturales a viviendas humanas.

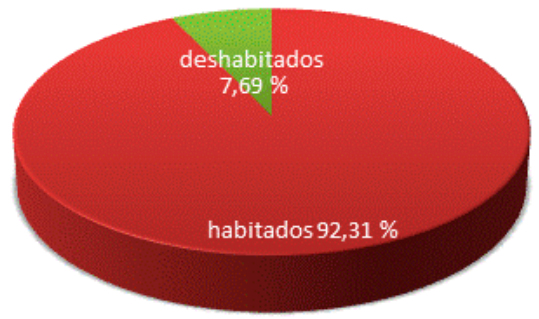

Figura 3. Porcentaje de refugios artificiales de murciélagos habitados ó deshabitados por el hombre. estos refugios artificiales los más poblados por murciélagos fueron los habitados por el hombre (Figura 3). Un $42 \%$ de ambos tipos de refugios, naturales y artificiales, se encontró dentro de la escala de menor altura, correspondiente a menos de $5 \mathrm{~m}$.

Se capturaron e identificaron 76 ejemplares de murciélagos. Se determinaron 9 especies diferentes distribuidas en 3 familias. Según su dieta alimenticia se clasificaron en especies hematófagas, frugívoras e insectívoras, esta última clase con mayor predominio (Tabla 3). Las especies Eumops patagonicus y Molossus rufus fueron halladas tanto en refugios artificiales como en naturales, mientras que Eumops perotis, Myotis albescens, Artibeus lituratus y Platyrrhinus lineatus solo en refugios arbóreos. Las especies halladas exclusivamente en refugios artificiales fueron Molossus molossus, Myotis nigricans y Desmodus rotundus, este último en un pozo de agua en zona periférica de la ciudad. Compartiendo refugio en el desván de un edificio se hallaron las especies Eumops patagonicus y Molossus rufus pertenecientes a la familia Molossidae. La ubicación de los refugios puede observarse en la Figura 4, tanto en zona céntrica como periférica de la ciudad, salvo refugios de la especie Eumops perotis y Desmodus rotundus, que se hallaron a $10 \mathrm{~km}$ fuera

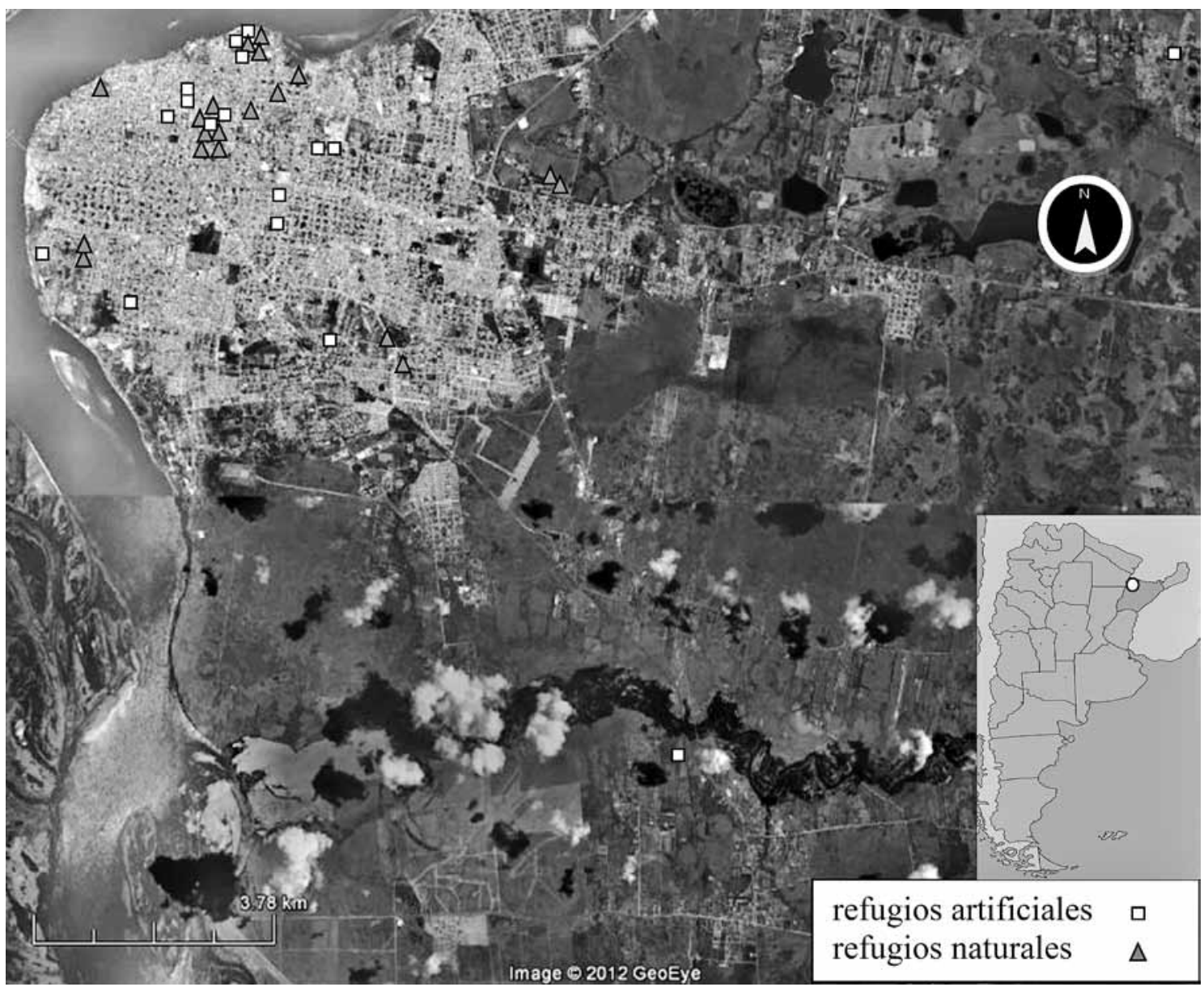

Figura 4. Localización de refugios de murciélagos en la Ciudad de Corrientes, Argentina. Imágenes tomadas del Google Earth, versión 6.2 - http://earth.google.es 
Tabla 3. Familias y especies de murciélagos capturados, en relación a diferentes tipos de refugios hallados y hábitos alimenticios.

\begin{tabular}{llccc}
\hline familias & especies & $\mathrm{n}$ & hábito & tipos de refugios \\
\hline Molossidae & Eumops patagonicus & 51 & insectívoro & A y N \\
& Eumops perotis & 1 & insectívoro & $\mathrm{N}$ \\
& Molossus rufus & 9 & insectívoro & A y N \\
& Molossus molossus & 6 & insectívoro & $\mathrm{A}$ \\
Vespertilionidae & Myotis albescens & 3 & insectívoro & $\mathrm{N}$ \\
& Myotis nigricans & 1 & insectívoro & $\mathrm{A}$ \\
Phyllostomidae & Desmodus rotundus & 3 & hematófago & $\mathrm{A}$ \\
& Artibeus lituratus & 1 & frugívoro & $\mathrm{N}$ \\
& Platyrrhinus lineatus & 1 & frugívoro & $\mathrm{N}$ \\
\hline
\end{tabular}

A: refugio artificial; N: refugio natural.

del límite trazado pero incorporados por sus cercanía al área de estudio.

\section{DISCUSIÓN}

Si bien la búsqueda de refugios se realizó durante las cuatro estaciones anuales, los resultados expuestos demuestran que tanto las denuncias realizadas por parte de la población como la identificación de los refugios a través de sus rastros por el grupo de investigación, fue más frecuente durante primavera, verano y otoño, con temperaturas templada a cálida, probablemente por el estado en que se encontraban los animales, machos activos sexualmente y hembras preñadas o con crías, pues en esta época la población es más numerosa y existe un mayor contacto con el hombre. No se encontró diferencia significativa en cuanto a la elección de refugios naturales o artificiales que utilizaban estos animales ( $p>0,05$ obtenido por chi-cuadrado con EPIDAT 3.1-OPS); sin embargo existió una marcada diferencia porcentual entre refugios artificiales deshabitados y habitados por el hombre, siendo este último ampliamente mayor.

La Ciudad de Corrientes se caracteriza por poseer un clima subtropical con elevadas temperaturas en el verano y de intermedias a altas en otoño y primavera, características que implican construcciones especiales para mantener ambientes confortables, contando la mayoría de ellas con cielorraso en sus techos, altillos o desvanes, lo que facilita las condiciones de refugio de los quirópteros con una buena amplitud para reproducirse y mantener sus crías. En cuanto a los refugios naturales, la especie arbórea más utilizada por los murciélagos fue Fraxinus americana comúnmente denominada fresno. Tal afinidad debería ser estudiada en profundidad: si bien es una especie dominante en la región, por otro lado podría ser la más elegida por las características de su estructura, dado que la densidad de ramas y hojas hace que se produzcan verdaderos microclimas en sus proximidades. Sus hojas, con un elevado valor nutritivo y ricas en derivados polifenólicos, dan pie a que se asienten animales en este microecosistema y puedan aprovechar su valor nutritivo, como es el caso de numerosos insectos e incluso mamíferos que se ven beneficiados por el podado de los fresnos.

Consideramos que existe una estrecha cercanía entre los quirópteros y el hombre ya que según los resultados presentados, por un lado la altura de ambos tipos de refugios es baja y por el otro, la distancia entre los refugios naturales y viviendas humanas habitadas es corta. Estos datos son importantes habida cuenta que si bien Desmodus rotundus es el reservorio de rabia por excelencia, también se ha comprobado que especies insectívoras y frugívoras pueden alojar el virus rábico y constituirse en reservorios ${ }^{3,8,12,18,19,25}$, por lo tanto también se deberían tomar recaudos a las exposiciones a especies no hematófagas. Adicionalmente, el acúmulo de sus heces favorece el crecimiento de Histoplasma capsulatum, agente etiológico de la histoplasmosis, micosis sistémica de considerable importancia en la salud pública ${ }^{13}$.

En cuanto a las características del entorno de ambos tipos de refugios, se encontraron en áreas con vegetación, farolas de luz artificial y alta densidad de insectos, coincidiendo con el mayor predominio de especies de murciélagos insectívoros. La escasa proximidad entre los refugios de murciélagos y la población humana es una característica también hallada en otros trabajos sobre ecología de quirópteros en zonas urbanizadas, demostrando la eficiente adaptabilidad de estos mamíferos en las ciudades ${ }^{12}$.

En cuanto a las técnicas de captura, si bien se contó con los elementos necesarios para tal fin, en el trabajo sobre terreno únicamente tuvo éxito la captura directa del animal con la mano y la técnica de trampa balde. Se verificó la imposibilidad de capturar con redes, probablemente debido a que las especies insectívoras de las familias Vespertilionidae y Molossidae usan con mayor frecuencia la ecolocalización y de esta manera evitan fácilmente las redes, a lo cual debería sumársele el hábito de alto vuelo que utilizan para alimentarse ${ }^{12,16}$.

Los 76 ejemplares de murciélagos capturados se distribuyeron en 3 de las 4 familias descriptas para la Provincia de Corrientes y se agruparon en 9 de las 29 especies registradas en la región ${ }^{5,7}$. Las especies frugívoras Artibeus lituratus y Platyrrhinus lineatus de la familia Phyllostomidae únicamente se encontraron en refugios naturales, mientras que el resto se distribuyó entre ambos tipos de refugios. Molossus rufus fue hallado en refugios artificiales y especies arbóreas demostrando su ya descripta adaptabilidad a ambos tipos de refugios ${ }^{4,6}$. En el desván de un edificio se identificaron dos especies en convivencia, Eumops patagonicus y Molossus rufus. El hábito de compartir refugio puede presentarse en diferentes especies, esta actitud comportamental fue corroborada en refugios artificiales como alcantarillas en especies del noroeste 
de Argentina, donde Anoura caudifer comparte refugio con Micronycteris microtis y por otro lado M. microtis lo hace con Glossophaga soricina ${ }^{10}$. El conocimiento de estas asociaciones contribuye a incrementar el acervo de estudios comportamentales de estos mamíferos. La conservación de los murciélagos es un importante aspecto a tener en cuenta porque como integrantes de la fauna intervienen en el equilibrio ecológico, pero cuando se encuentran en estrecha convivencia con el hombre, también participan en la transmisión de algunas enfermedades.

En conclusión, los resultados obtenidos aportan nuevos conocimientos acerca de las numerosas especies de murciélagos que habitan la zona bajo estudio, así como su estrecha relación con los seres humanos y su gran adaptabilidad para desarrollarse en proximidades de sus viviendas, sin ser la presencia de sus moradores un impedimento. La investigación también contribuye al conocimiento de la ecología urbana de quirópteros a nivel regional.

\section{REFERENCIAS}

1. Acha PN, Szyfres B. 2003. Zoonosis y enfermedades transmisibles al hombre y a los animales domésticos, $3^{\circ}$ ed, Publ. Organización Panamericana de la Salud, Washington, vol II, p. 351-383.

2. Alberico M, Saavedra CA, García-Paredes H. 2005. Murciélagos caseros de Cali (Valle del Cauca, Colombia). Caldasia 27: 117-126.

3. Almeida MA, Aguiar EA, Matorelli LF, Silva MM. 1994. Diagnóstico laboratorial de raiva em quirópteros realizado em área metropolitana na região sudeste do Brasil. Rev Saúde Públ 28: 341-344.

4. Barquez RM, Giannini NP, Mares MA. 1993. Guide to the bats of Argentina, Publ. Oklahoma Museum of Natural History, University of Oklahoma, Norman (USA), p. 119.

5. Barquez RM. 2004. Murciélagos (Chiroptera-Mamalia) de la Mesopotamia Argentina. Temas de la biodiversidad del litoral fluvial argentino (Instituto Superior de Correlación Geológica INSUGEO), Miscelánea 12: 369-378.

6. Barquez RM, Díaz MM. 2009. Los murciélagos de Argentina: clave de identificación, Ed. Magna, Tucumán (Argentina), p. 69.

7. Barquez RM, Sánchez MS, Sandoval ML. 2011. Nuevos registros de murciélagos (Chiroptera) en el norte de Argentina. Mastozool Neotrop 18: 11-24.

8. Carrera N, Quevedo N, Urbieta S, San Miguel MC, Irala L. 2008. Rabia en murciélagos frugívoros e insectívoros, Villa Florida, Departamento de Misiones, Paraguay 2006. Rev Inst Med Trop 1: 7-14.

9. Cian DE, Cabral EL, Passicot CO, Ferber OF. 2001. Guía para el reconocimiento de plantas del Parque Mitre. Publ. Facultad de Ciencias Exactas, Naturales y Agrimensura UNNE (Corrientes, Argentina), $150 \mathrm{p}$.
10. Diaz MM, Barquez RM. 2009. Primer registro de $M i$ cronycteris microtys (Phyllostomidae, Phyllostominae) para la Argentina. Chiroptera Neotrop 15: 461-465.

11. Dimitri MJ, Leonardis RF, Biloni JS. 1997. El nuevo libro del árbol, El Ateneo, Buenos Aires, tomo I, p. 119.

12. Dos Reis NR, Passos I, Peracchi AL. 2006. Morcegos (Chiroptera) da área urbana de Londrina, Paraná, Brasil. Rev Bras Zool 19: 739-746.

13. Galvão Dias MA. 2009. Aspectos epidemiológicos de Histoplasma capsulatum em morcegos em areas urbanas do estado de São Paulo. Tese de Mestre en Biotecnología, Instituto Butantan, São Paulo, p. 89.

14. Hoff GL, Bigler WJ. 1981. The role of bats in the propagation and spread of histoplasmosis: a review. $J$ Wildlife Dis 17: 191-196.

15. Instituto Nacional de Estadística y Censos - INDEC, 2010. http://www.indec.gov .ar/ 24/04/2012.

16. Kalko EK, Handley CO. 2001. Neotropical bats of the canopy: diversity, community structure, and implications for conservation. Plant Ecol 153: 319-333.

17. Medina A, Harvey C, Sánchez D, Vilchez S, Hernández B. 2003. Diversidad y composición de chirópteros en un paisaje fragmentado de bosque seco en Rivas, Nicaragua. Rev Encuentro (Managua) 36: 24-43.

18. Núñez M, Aldaz JJ, Escobar H, Cuadros ME. 2001. Primer hallazgo de rabia silvestre en el murciélago insectívoro Eptesicus brasiliensis en Cali, Colombia. Rev Asoc Colomb Cs Biológ 12: 57-61.

19. Núñez CL, Barona MH, Cuadros ME, Ospina NF. 2002. Zoonosis transmitidas por murciélagos y su impacto en la salud humana y animal en Santiago de Cali. Memorias XVII Congr Cs Biol, Pasto, Nariño (Colombia), p. 118.

20. Otero JA, Arango S, Restrepo M M, Alberico M, Gutiérrez H, Márquez M, Oliveros A, Escobar H, Losada E, Sardi R, Valencia D, Sardi H, Buitrago L. 1993. Prevalencia de virus rábico en quirópteros del área municipal de Cali, Colombia. Colombia Méd 24: 137-141.

21. Servicio Meteorológico Nacional, Secretaria de Planeamiento, Ministerio de Defensa. Argentina 2012. http:// www.smn.gov.ar/?mod=pron\&id=49.

22. Silva MM, Harmani MN, Gonçalves EF, Uieda W. 1996. Bats from the metropolitan region of São Paulo, Southeastern Brazil. Chiroptera Neotrop 2: 39-41.

23. Silva Taboada G. 1979. Los murciélagos de Cuba, Ed. Academia de Ciencias de Cuba, La Habana, p. 423.

24. Uieda W. 1995. The common vampire bat in urban environments from Southeastern Brazil. Chiroptera Neotrop 1: 22-24.

25. Uieda W. 1998. Rabies in the insectivorous bat Tadarida brasiliensis in soulheastern Brazil. Rev Saúde Públ 32: 484-485. 